\title{
Relationship between Organizational Strategy and Leadership Style in Performance Efficiency
}

\author{
Md. Habibur Rahman*, Tonmoy Dey, Md. Al-Amin \\ Lecturer, Department of Management Information Systems, Noakhali Science and Technology University, Noakhali, BANGLADESH \\ *E-mail for correspondence: habib.nstum@gmail.com
}

https://doi.org/10.18034/abr.v9i1.221

\begin{abstract}
The strategy of an organization reflects the probable ways to achieve the objectives of the organization. Successful organization is the result of effective implementation of organizational strategy and leadership. The study has examined the relationship between organizational strategy and leadership to achieve performance effectiveness and objectives of the organization. In this paper, extensive studies are conducted on different peer reviewed journals which is based on leadership and organizational strategy with performance. The findings of different authors are taken into consideration to show the cause effect relationship between organizational strategy and performance. This study establishes different proposition and validated those proposition with the analysis of different findings of different authors.
\end{abstract}

Key words: Organizational strategy, leadership, performance, relationship, style

\section{INTRODUCTION}

The success of an organization depends on the adaptation of organizational strategy and leadership styles by the top management and executives of the organization with the changing environment. Leadership remains an art of corporate organization. Leadership has emerged as the most widely studied aspects of the organizational issue for performance effectiveness with the implementation of organizational strategy. Interest in strategic leadership has been increasing in recent years (Finkelstein \& Hambrick, 1996; Hitt \& Ireland, 2002; Zaccaro \& Klimoski, 2001). Effective performance requires a cooperative effort by multiple leaders in an organization. Leadership is the art of getting things done by others through coordinated efforts. That is why it is being assumed that leadership strategies will translate into the subordinate's performances and the achievement of success by the firm (Sunday et al., 2014). An effective organizational strategy will identify the leadership style that will accelerate the growth of the organization. A strategy is the actions of people of the organization that are taken by the leader of the organization to accomplish objectives (Caroline, 2002). According to Peter Drucker "leadership is all about results". The relationship between leaders and workers or workers' performances is significantly influenced by the leadership style adopted by the leader. According to Michael (2011) leadership has a direct cause and effect relationship between organizations and their success. Leaders determine values, culture, change tolerance and employee motivation with strategies to achieve the objectives of the organization. This paper will present an integration of leader ideas, strategic thinking with the organizational strategy to reach performance efficiency. Performance efficiency of an organization is defined as the extent to which it can survive, perform its objectives and maintain favorable earnings, financial resources, and asset value. Effectiveness of the organization depends on three primary performance determinants; (1) Efficiency and process reliability, (2) human capital and (3) adaptation to the external environment. The performance determinants are influenced by the decision and actions of leaders which are known as leadership styles (Yukl, 2008).

\section{Problem statement}

Every organizations wants to be successful in this competitive world. They formulate plan, strategy, policies, and programs to reach the goals. They also set leadership strategy for the organization. But matching between leadership and organizational strategy always remain uncovered in most of the organization in achieving performance efficiency. This study will examine how the relationship between leadership and organizational strategy can improve performance efficiency. 


\section{Objectives of the study}

The Primary objectives of the study are to find out the relationship between organizational strategy and adopting leadership style by the organization for performance efficiency of the operations. The study also has some secondary objectives:

- To find out the impact of organization's strategies in achieving the desired performance.

- To determine the importance of selecting leadership styles by organization's strategies.

- To examine how performance efficiency can be achieved through leadership choice.

- To establish strategies for choosing leadership style to meet performance goals.

\section{LITERATURE REVIEW}

Organizational strategies show the path to achieve the objectives of the organizations. On the other hand, leadership is a management skill which involves the ability to encourage a group of people to common goals. According to Michael (2011) leadership has a direct cause and effect relationship upon organizations and its success. Most of the empirical studies on leadership effectiveness during the past half-century involved middle or lowermiddle managers rather the top management of the organization (Yukl, 2006). The research conducted during the past half-decade was on how an individual leader can influence workers to work more or perform better than initially expected. During the past, most of the empirical research on leadership behavior was gained by the theories of chrematistic and transformational leadership (Bass, 1985). A large number of studies indicate that transformational leadership behavior can accelerate motivation and performance of subordinates. According to Bass (1985), there are four dimensions of leadership that are used to accomplish the transformation of subordinates, of the organization, attributed charisma and idealized influence, inspired motivation, individualized consideration, and intellectual stimulation. A 2008 study found that only 36 percent of the surveyed companies found prepared to fill leadership position immediately (Harvard Business Review, June 2009). Deal \& Kennedy believes that the roles of the leadership are key while addressing the issue of organizational change and effective leader can bring effective change for an organization (Deal \& Kennedy, 2000). Leader thinks strategically for performance effectiveness. Contingency theories argued and the empirical studies concurred that the effectiveness of an organization is influenced by the "degree of fit" between the requirement of the environment and the characteristics of an organization. The extent to which a leader makes appropriate changes in strategies and tactics provides another indicator of flexible and adaptive leadership (Yukl, 2008., pp. 81-93).
Organizations performance determinants have been studied for several decades and, theory of management, and organization are a central topic in the literature (Melcher, 1967; Katz and Khan 1978; Mintzberg et al., 1976). The literature on corporate strategy (Wernerfelt and Barney, 1991; Teece, et al. 1997) and many practitioneroriented books on studies of effective firms also provided insights about the determinants of organizational performance.

The efficiency of the organization can be improved with the stability of the operation for a definite time. Leading contribution to performance efficiency with the proper implementation of organizational strategies are studied by Miles et al.'s (1978) in strategic types (Prospectors, Analyzers, Defenders and Reactors) in set of generic strategies" (Cost Leadership, Differentiation and Focus) in high-performance "gestalts. There are many ways for improving performance efficiency, and they include redesigning work processes, using new technology, reducing the cost of energy or materials, reducing excess inventory and reducing the cost of labor (Yukl, 2008).

\section{Methodology OF THE Study}

The aim of research methodology is to give the plan of work to conduct research. There are two ways of conducting research. The first one is empirical research or study which is based on data collection and analysis of data for the research purpose that will fulfill the hypothesis developed by the researcher. Another form of research is conceptual research which focuses on the concept or theory that describes the phenomenon to be studied. In conceptual research, nothing is experiments, but the observations of others may use to validate the proposition. In this research, the findings of different researchers are taken into account to prove the cause-effect relationship between organizational strategy and leadership style in performance efficiency. It is a peer reviewed journal based on different proposition and establishing logic on behalf of those proposition. Finally, conclusions on the overall propositions for the research problem.

Figure 1: Conceptual research framework

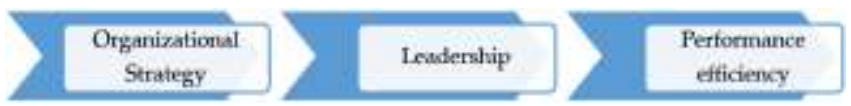

Proposition of the study

Proposition 1: Organizational strategy and performance efficiency.

Proposition 2: Leadership style has an impact on performance efficiency.

Proposition 3: The performance determinants can be enhanced by relevant leadership style.

Proposition 4: The performance determinants can be enhanced by an organizational strategy. 
Proposition 5: Joint efforts of organizational strategy and leadership styles increase the value of the performance determinants.

Proposition 6: The performance of the organization is better with the collective influence of leaders at the different level in strategy formulation and implementation process.

Proposition 7: Differential leadership styles help in finding integrative solutions for tradeoffs involving performance determinants.

\section{Discussion AND RESULTS}

Proposition 1: Organizational strategy and performance efficiency

Lewis (2008) argued that a strategy is an indispensable tool for an organization's success. The strategy enables an organization to initiate and implement activities that could help exert control over its destiny. Dezember at el. (2005) argued that for an organization to manage its strategies well in practice a structure is required. Lewis at el. (2001) in his opinion the structure of an organization as an authority and responsibility for result achievement. A leader exercise authority and responsibility through leadership style. Slater and Olsen (2005), found that a firm's performance is strongly influenced by how well it's strongly is matched with its structure and behavior of workers. A leader influences the behavior of workers. Mousavi et al. (2011) defined leadership as the process by which a subordinate is influenced to reach a target. Fry (2003) defined leadership as the use of a strategy to motivate staffs and enhance their potential for growth and development. Stogdill and Coons (1957) defined leadership style as a method and ability that aims to realize organizational targets and have an impact on organizational performance. Strategic topologies are the frameworks that identify multiple competitive strategies to business units. Typologies provide a theoretical basis for identifying strategic groups across industries (Zamani, et al., 2013). Guth and MacMillan (1986), has found that motivation by leader serves as a bridge between the effective implementation of business strategy and organizational performance. Slater and Olsen (2001) argued that no matter how super a strategy is; it has to be well implemented to achieve the desired results. They believe that effective implementation of strategy is necessary for organization's ability to achieve and maintain a competitive advantage over other organizations. Different authors have given their opinion that the effective strategy planning and implementation ensure positive contribution to the over-all performance of the organization. So, according to findings of different researchers that organizational strategy and performance efficiency are positively related.

Proposition 2: Leadership style has an impact on performance efficiency

The performance of the organization is improved by a leader's behavior. One form of influence is the use of specific leadership behaviors in interactions with workers, followers, and outsiders. Organizational performance is secondly influenced by the decision about management programs and systems, and organizational structure. The third form of influence involves decisions about the competitive strategy of the organization (Yukl, 2008). Voon et al. (2011) argued that effective leadership is considered an active way to develop management and improve organizational performance. It is an issue to understand the effects of performance because researchers such as Zhu et al., (2005) have considered leadership to be a driving force behind the management performance of any organization. Scholars have suggested that behaviors of a leader can have improved performance when organizations are faced with such new challenges (Judge and Piccolo, 2004). So, the leadership style should be compatible with the organizational strategy to ensure performance efficiency. Leadership is the life-blood of any organization, and its importance cannot be ignored or underestimated. Voon et al. (2011) argued that the influence of leadership originates from the nature and behavior of the leader. Mehra et al. (2006) mentioned that organizations that are looking for efficient ways to outperform their competitors often focus on leading. The leader-centered perspective has offered helpful insights into how leadership is related to team performance (Zhu et al., 2005). Researchers (McGrath and McMillan, 2000) have explored the strategic role of leadership on how leadership paradigms and leadership behavior can be used to improve organizational performance. So, the leadership style of the leader motivates the workers to work for the organization to ensure performance efficiency.

Proposition 3: The performance determinants can be enhanced by relevant leadership style.

There are different leadership styles like task-oriented, relationship-oriented, and change-oriented. Each leadership style has some objectives which align with the three determinants of organizational effectiveness. Taskoriented behaviors are most useful for improving efficiency, change-oriented behaviors are most useful for improving adaptation, and relations-oriented behaviors are most useful for improving human resources and relations. All of the three leadership styles have implications for organizational effectiveness (Yukl 2008).

Task-oriented behaviors include short-term planning and scheduling of work activities, determining resources and staffing requirements, assigning tasks, clarifying objectives and priorities, emphasizing the importance of efficiency and reliability, directing and coordinating activities, monitoring operations and dealing with day-today operations (Yukl 2008). Task-oriented styles are used for improving productivity and reducing costs by eliminating unnecessary activities, duplication of efforts, wasted resources, errors, etc. They also made the opinion that task-oriented leader can enhance the performance of subordinates and small groups (Bass, 1997; Yukl, 2006). 
Change-oriented leaders identify the external factors like opportunities and threats, also interprets events explaining why change is needed; articulates an inspiring vision; takes the risk to promote change; builds a coalition of supporters for change and determines how to implement a new initiative for change (Yukl, 2006). Research on change-oriented aspects of leadership styles such as inspirational motivational and intellectual stimulation prove that change-oriented leadership style can increase individual and team performance (Lowe et, al., 1996). Creativity and innovation determinants research provides additional evidence for the relevance of change-oriented leadership (Mumford et al., 2002; ReiterSalmon and sllies, 2004).

Proposition 4: The performance determinants can be enhanced by an organizational strategy.

Organizational strategy can ensure the performance (adaptation). Organizational strategies include management programs, systems, structural forms, etc. Different types of improvement programs, structural forms, and management and marketing systems can be introduced to accelerate the performance determinants and organizational effectiveness (Yukl and Lepsinger, 2004). Leader of subunits has more authority than lowerlevel managers to modify or implement management programs, systems and structural forms (Hambrick et al., 1996). Coordinated efforts of the leader at all levels of the organization is necessary to implement an organizational strategy effectively. Efficiency is also influenced by aspects of formal organizational structure like formalization, standardization and the use of specialized subunits (Mintzberg et al., 1976).

Many management systems and improvement programs fail because they are irrelevant, poorly implemented, or incompatible with the organizational culture and competitive strategy (Abrahamson, 1996; Abrahamson \& Fairchild, 1999; Benner and Tushman, 2003; Straw and Epstein, 2000).

Proposition 5: Joint efforts of organizational strategy and leadership styles increase the value of the performance determinants.

The joint efforts of leader behaviors and management programs (organizational strategy) can influence culture of the organization (Schein, 1992) to enhance performance of the organization. Strong corporate culture can enhance organizational performance if the shared values and beliefs are consistent with the strategy to adapt to the environment (Detert et al., 2000). A leader can influence the culture of the organization through different strategy (management programs and systems) involving workers' selection, socialization, training, performance appraisal and rewards (Yukl, 2008). The strategy (Management programs and structures) can also limit the use of leadership styles. Because, it is difficult to empower subordinates when they follow elaborated rule and standard procedures for doing work (Spreitzer, 1996). A Strategy can also enhance the effects of a leader's behavior. Encouraging thinking or intellectual stimulation is likely to increase innovation when an organization has a program to facilitate innovation, a climate of psychological safety for risk-taking and innovative ideas about products or process will be supported (Yukl, 2008). Strategy formulation is facilitated by the use of specific leadership styles such as monitoring the external environment, assessing the threats and opportunities, identifying core competencies and evaluating alternative strategies. Some programs and systems for monitoring the external environment provide additional information necessary to identify an appropriate strategy for the organization. Several leadership styles can be used to implement a new strategy or change (Yukl, 2006). So, joint efforts in organizational strategy and leadership styles increase performance by increasing the value of performance indicators.

Proposition 6: The performance of the organization is better with the collective influence of leaders at the different level in strategy formulation and implementation process.

There are several ways top management can increase the involvement of middle and lower level managers (leaders) in making an important decision (Sundaramuthy \& Lewis, 2003). Managers at different level can be involved in face-to-face or virtual meetings about strategic decisions. A relevant strategy can be used to encourage and support proposals from lower-level managers for improving efficiency. If an organization formulates a strategy that is incompatible, the performance of the organizations will also suffer. Leadership scholars assume that strategic decisions are made by CEO and influence cascade down the authority hierarchy as managers at each level interact with their subordinates (Yammarino, 1994). So, the organizational strategy should be formulated considering in mind the existing resources of the organizations, and the knowledge and skills of the leaders to implement such strategy and it is also necessary to rearrange the organogram by the strategy to introduce the most suitable of leadership. Meaningful participation by people who have relevant expertise can increase decision quality and commitment to implement the strategy successfully (Vroom \& Jago, 1988). That is the collective influence of leaders at a different level of the organization in the strategy formulation and implementation to bring performance efficiency in the operation process.

Proposition 7: Differential leadership styles help in finding integrative solutions for tradeoffs involving performance determinants.

The need for coordination and cooperation among managers and leaders is important when different units of the organization are independent but also differentiated about their functions or objectives. Top management teams 
with specialized roles related to the performance determinants (Edmondson et al., 2004; Pettigrew, 1992). If there is no advocate for a performance determinant in the top management team, it may not receive adequate consideration in strategy formulation, and implementation. When members of the top management team have differentiated roles, the head of the organization may have primary responsibility for achieving integration, and it can be facilitated with the use of appropriate decision processes (Edmondson et al., 2004). But making decisions jointly yield high-quality decisions if the executives or leaders or managers have an accurate, shared "mental model" about the determinants of organizational performance (Kilmoski and Mohammed, 1994). The leaders of specialized subunits in an organization often have different knowledge, skills, abilities, experience, priorities, etc. regarding performance determinants of the organizations, and their decision is often based by their unique perspective (Yukl, 2008). Companies with a strong relevant "core ideology" are more likely to survive and successful over a long period. Differential leadership styles of a leader about the organizational strategy related to high performance. So, proposition seven is supported.

\section{Concluding Remarks}

Throughout study, the review of different literature examined that how leadership and organizational strategy together ensure performance efficiency. To achieve performance efficiency and effectiveness in today's turbulent, uncertain environment, organizations need leaders who are flexible and adaptive. These leaders must be able to understand the complex relationships among performance determinants and recognize what can be done to influence them beneficially. Leaders of the organization must keep themselves prepared to modify their leadership behavior, the competitive strategy, and the formal programs and structures to meet the challenges that confront them in an increasingly turbulent and uncertain manner with the strategy of the organization to achieve performance effectiveness. The strategy of the organization influences on performance of the organization. At the same time the leadership strategy of the leaders also influences on the performance determinants. Leaders determine the styles to be followed with the strategy of the organization to ensure that performance objectives will be achieved. Different scholars have given their opinion that leadership styles will positively or negatively influence the performance of the organization. Howell and Frost (1989) cited in Fu-Jin et al., 2011) also confirm that there is a positive relation between leadership style and organizational performance. Roslan et al., (2013) is split regarding whether leadership helps enhance organizational performance. Ojokuku et al., (2012) found that styles of leadership demoralize employees and this may lead to high turnover intension. So, to minimize the employee turnover and to increase the performance of the organization, leadership styles will play an important role. Leadership styles are the strategy of the leader to follow some specific procedures to motivate and influence people of the organization. Organizational strategy is the specific activities to be followed to achieve the performance goal of the organization.

\section{REFERENCES}

Abrahamson, E. (1996) "Management fashion," Academy of Management Review (21), pp 254-285.

Abrahamson, E., and Fairchild, G. (1999) "Knowledge industries and Idea Entrepreneurs: New Dimensions of Innovative Products, Services, and Organizations," in: The 18 Entrepreneurship Dynamic in Industry Evolution, E. Romanelli (ed.), Stanford University Press, Stanford, CA.

Bass, B.M. (1985) leadership and performance beyond expectations. New York: Free Press.

Bass, B.M. (1997). Transformational leadership: Industrial, military, and educational impact. Mahwah, NJ: Lawrence Erlbaum Associates.

Benner, M.J. and Tushman, M.L. (2003), Exploitation, Exploration, and Process Management: The Productivity Dilemma Revisited, The Academy of Management Review, Vol. 28, No. 2 (Apr.), pp. 238-256

Caroline, H. (2002). Executive Coaching: The Leadership Development Tool of the Future.

Deal. T \& Kennedy. A (2000) Corporate Cultures, The Rites and Rituals of Corporate Life. Perseus Publishing

Detert, J.R., Schroeder, R.G. \& Mauriel, J.J. (2000). A framework for linking culture and improvement initiatives in organizations. The Academy of Management Review, 25(4), 850-863.

Dezember, O., Slater, S. F. \& Hult, T. M. (2005). "The importance of structure and process to strategy implementation", Business Horizons, 48, 4754.

Edmondson, A., Roberto, M. A., Bohmer, R. M., Ferlins, E. M., \& Feldman, L. (2004). The Recovery Window: Organizational Learning Following Ambiguous Threats in High-Risk Organizations. In M. Farjoun \& W. H. Starbuck (Eds.), Organization at the Limit: NASA and the Columbia Disaster. London: Blackwell.

Finkelstein, S., \& Hambrick, D.C. (1996). Strategic leadership: Top executives and their effects. Minneapolis: West Publishing.

Fry, L. W. (2003). Towards a Theory of Spiritual Leadership. The Leadership Quarterly, 14, 693-727.

Fu-Jin .W, Shieh .C \& Tang, M. (2011). Effect of leadership style on organizational performance as viewed from human resources management strategy. African journal of business management, 4(18), 3924-3936.

Guth W. D. and MacMillan, L.C. (1986), Strategy Implementation Versus Middle Management Self-Interest, Strategic Management Journal, Vol. 7, No. 4, pp. 313-327

Hambrick, D. C., Cho, T. S. and Chen M. J. (1996). 'The influence of top management team heterogeneity on firms' competitive moves'. Administrative Science Quarterly, 41, 659-84.

Hitt, M.A., \& Ireland, R.D. (2002). The essence of strategic leadership: managing human and social capital. Journal of leadership and organizational studies, 9(1), 3-14.

Howell, J. M., \& Frost, P. J. (1989). A laboratory study of charismatic leadership. Organizational Behavior and Human Decision Processes, 43(2), 243-269. http:/ /dx.doi.org/10.1016/0749-5978(89)90052-6 
Judge, T. A., \& Piccolo, R. F. (2004). Transformational and Transactional Leadership: A Meta-Analytic Test of Their Relative Validity. Journal of Applied Psychology, 89(5), 755768. http:/ / dx.doi.org/10.1037/0021-9010.89.5.755

Katz, D. \& Kahn, R.L. (1978). The social psychology of organizations. New York: John Wiley.

Klimoski, R. and Mohammed, S. (1994) Team Mental Model: Construct or Metaphor? Journal of Management, 20, 403437. https://doi.org/10.1177/014920639402000206

Kotter, J. P., \& Schlessinger, L. A. (2008). Choosing strategies for change. Harvard Business Review, 130-139. (p. 132).

Lewis, I. (2008). "The quantum skills model in management: a new paradigm to enhance effective leadership". Leadership and Organizational Development Journal, 22(6): 264-273.

Lewis, P. S., Goodman, S. H. \& Fandt, P. M. (2001). Management, challenges in the 21st century. USA: South Western Publishing.

Lowe, K. B., Kroeck, K. G., \& Sivasubramaniam, N. (1996). Effectiveness correlates of transformation and transactional leadership: A metaanalytic review of the MLQ literature. Leadership Quarterly, 7, 385- 425.

McGrath, G. R., \& MacMillan, I. C. (2000). Entrepreneurial Mindset: Strategies for Continuously Creating Opportunity in an Age of Uncertainty. Harvard Business School Press Books.

Mehra, A., Smith, B. R., Dixon, A. L., \& Robertson, B. (2006). Distributed leadership in teams: The network of leadership perceptions and team performance. The Leadership Quarterly, 17(3), 232-245.

Melcher, A.J. (1976). Structure and process of organizations: a systems approach. Englewood Cliffs, NJ: Pretice Hall.

Michael. A. (2011). Leadership style and organizational impact. Retrieved from: http://ala-apa.org/.

Miles, R. E, Snow, C. C, Meyer, A. D., Coleman, H. J, Jr. (1978) Organizational Strategy, Structure, and Process, The Academy of Management Review, 3 (3), pp. 546-562.

Mintzberg, H., Raisinghani, D., \& Theoret, A. (1976). The structure of unstructured decision processes. Administrative Science Quarterly, 21, 246-275.

Mousavi, S. H., Heidary, A., \& Pour, F. K. (2011). The relationship between leadership styles and physical education teachers'creativity. International Journal of Academic Research in Business and Social Sciences, 1(3), 82-84. http://dx.doi.org/10.6007/ijarbss.v1i2.19

Mumford, M.D., Scott, C.M., Gaddis, B., \& Strange, J.M. (2002). Leading creative people: orchestrating expertise and relationships. The Leadership Quarterly, 13, 705-750.

Ojokuku, R.M., Odetayo, T.A., Sajuyigbe, A.S. (2012), Impact of Leadership Style on Organizational Performance: A Case Study of Nigerian Banks, American Journal of Business and Management. Volume 1, Issue 4, Pages 202-220.

Pettigrew, A. M. (1992). On studying managerial elites. Strategic Management Journal, 13, 163-182.

Reiter-Palmon, R., \& Illies, J.J. (2004). Leadership and creativity: understanding leadership from a creative problem-solving perspective. The leadership quarterly, 15, 55-77.

Roslan, A. A., Abdullah, M. H., Tajudin, A., \& Mahmood, R. (2013). The effect of leadership styles on the business performance of SMEs in Malaysia. International Journal of Economics Business and Management Studies, 2(2), 45-52.
Schein, E.H. (1992). Organization culture and leadership, $2^{\text {nd }}$ edition San Francisco: Jossey Bass.

Slater, S. F. \& Olson, E. M. (2001). Marketing's contribution to the implementation of business strategy: An empirical analysis. Strategic Management Journal, 22(11): 1055-1068.

Spreitzer, G. M. (1996). Social structural characteristics of psychological empowerment. Academy of Management Journal, 39(2), 483-504. http:/ /dx.doi.org/10.2307/256789

Stogdill, R.M. \& Coons, A.E. 1957. Leader Behavior it"s Description and Measurement. Ohio: Bureau of Business Research, The Ohio State University, 88, 1-27.

Straw B.M. and L.D. Epstein, 2000. What bandwagons bring: Effects of popular management techniques on corporate performance, reputation and CEO pay. Administrative Science Quarterly, 45: 523-556.

Sundaramurthy, C. and Lewis, M. (2003). Control and Collaboration: Paradoxes of Governance, Academy of Management Review, Vol. 28, No. 3, https:/ / doi.org/10.5465/amr.2003.10196737

Sunday, K.J., Adekunle, I. \& Roseline, O (2014). Organizational Survival: The effects of leadership skill and strategy. Science Journal of Business and Management, 2(2), 44-49.

Teece, D. J., Pisano, G., \& Shuen, A. (1997). Dynamics capabilities and strategic management. Strategic Management Journal, 18, 509-533.

Voon, M. L., Lo, M. C., Ngui, K. S. \& Ayob, N. B. (2011). The influence of leadership styles on employees' job satisfaction in public sector organizations in Malaysia. International Journal of Business, Management and Social Science, 2(1), 24-32

Vroom, V. H., \& Jago, A. G. (1988). The new leadership: Managing participation in organizations. Englewood Cliffs, NJ, US: Prentice-Hall, Inc.

Wernerfelt, B. \& Barney, F. (1991). "Factors affecting organizational performance: A five country comparison", Marketing Science Instituted Report, pp. 97-108

Yammarino, F. J. (1994). Indirect leadership: Transformational leadership at a distance. In B. M. Bass \& B. J. Avolio (Eds.), Improving organizational effectiveness through transformational leadership (pp. 26-47). Thousand Oaks, CA, US: Sage Publications, Inc.

Yukl G (2006). Leadership in organizations (5th ed.). Upper Saddle River, NJ: Prentice-Hall.

Yukl G (2008). The Leadership Quarterly 19(2008) 708-722.

Yukl, G., \& Lepsinger, R. (2004). Flexible leadership: Creating value by balancing multiple challenges and choices. San Francisco, CA: Jossey-Bass.

Zaccaro, S.J., \& Klimoski, R.J. (2001). The nature of organizational leadership: understanding the performance imperatives confronting today's leaders. San Francisco, CA: Jossey-Bass.

Zamani Sh, Eslami BR and Kazemi M (2013). Tehran Stock Exchange index value at risk calculation using the extreme value theory. Journal of Stock Exchange, 6(21): 115-136.

Zhu, W., Chew, I., and Spangler, W., (2005). "CEO transformational leadership and organizational outcomes: The mediating role of human-capital-enhancing human resource management, The Leadership Quarterly, Vol. 16, pp.39-52

$--0--$ 